\title{
Choroidal atrophy-alopecia syndrome
}

INSERM

\section{Source}

INSERM. (1999). Orphanet: an online rare disease and orphan drug data base. Choroidal atrophy-alopecia syndrome. ORPHA:1433

Choroidal atrophy - alopecia is a very rare ectodermal dysplasia syndrome, characterized by the association of choroidal atrophy (sometimes regional), together with other ectodermal dysplasia features including fine and sparse hair, absent or decreased lashes and eyebrows, and possibly mild visual loss and dysplastic/thick/grooved nails. 